\title{
Competence-Based Approach in Value Chain Processes
}

\author{
Rodrigo Cambiaghi Azevedo ${ }^{1}$, Sophie D’Amours ${ }^{1}$, and Mikael Rönnqvist ${ }^{2}$ \\ ${ }^{1}$ Université Laval, For@c Research Consortium, CIRRELT - Centre Interuniversitaire de \\ Recherche sur les Réseaux d'Entreprise, Quebec, QC, G1V 0A6, Canada \\ \{Rodrigo.Cambiaghi, Sophie.DAmours\}@cirrelt.ca \\ ${ }^{2}$ Norwegian School of Economics and Business Administration, \\ NO-5045 - Bergen, Norway \\ Mikael.Ronnqvist@nhh.no
}

\begin{abstract}
There is a gap between competence theory and value chain processes frameworks. While individually considered as core elements in contemporary management thinking, the integration of the two concepts is still lacking. We claim that this integration would allow for the development of more robust business models by structuring value chain activities around aspects such as capabilities and skills, as well as individual and organizational knowledge. In this context, the objective of this article is to reduce this gap and consequently open a field for further improvements of value chain processes frameworks.
\end{abstract}

Keywords: Value Chain Management, Business Process, Competence.

\section{Introduction}

Value chain management and the competence-based approach are considered to be two distinct bodies of knowledge and have been intensely debated in academic and practical fields in recent years. The former, here considered as synonymous with supply chain management, is defined as a management philosophy where the coordination and optimization of material, information and financial flows happen not within a business unit, but among the involved parts of a collaborative network [15]. At the centre of this philosophy lays the concept of business process and this explains why academia and practitioners intensively debate the most suitable collection of processes when implementing value chain business models [8].

In an analogous fashion, the competence-based approach has emerged in recent decades as a basis for new insights into the nature of inter-firm competition and potential sources of competitive advantage [12]. Defining "competence" as the ability to sustain the coordinated deployment of assets in ways that help a firm achieve its goals, its study investigates the association between company internal characteristics and market value creation.

In spite of the importance of competence theory for contemporary management thinking, we observed that its wisdom has still not been explored in the field of value chain processes. This article aims to reduce this gap and consequently open a field for 
further improvements in terms of value chain processes frameworks. In order to do so, we organize this article as follows: first, we discuss value chain processes and this aims to identify where the competence-based approach might be applicable. Second, we depict a core processes framework for value chains networks. This framework forms the backbone for competences to support the achievement of the firm's goals. Third, competence theory is introduced and its construction around value chain management processes is proposed. Finally, the main findings of the research are outlined.

\section{Classifying Value Chain Processes}

Hammer [6] defines a business process as a collection of activities that takes one or more kinds of input and creates an output that is of value to the customer. Davenport and Short [4] reiterate this definition by affirming that business processes have two important characteristics: (a) they focus on their customer and (b) they cross organizational functions. More recently, the value chain management concept has expanded the second characteristic to include an inter-organizational approach among different elements of a value chain.

Some classifications of business processes can be found in the literature [1]. One of the most frequent classifications is associated with the purpose of the business process inside an organization or a value chain. Regarding this subject, Davenport [5] categorized business processes as operational or managerial. More recently, Mentzer et al. [11] have expanded this classification by proposing three main categories: (i) core processes that are needed to realize business goals by enabling goods and services to reach an external customer; (ii) support processes that are needed to make the core processes work as well as possible, but which are not critical to the success of the company; (iii) management processes which are broader knowledge domains used to control and coordinate the core and support processes.

A common feature in the literature is that core processes are defined as a set of a few processes vital for a company's survival. They present structured and continuous patterns of performance [1;5]. In contrast to core processes, management processes are considered unstructured and discontinuous, which in a certain way, means the term becomes an oxymoron [5].

The distinction between core and management processes is supported by the coordination theory proposed by Malone and Crowston [10]. According to the authors, this theory endeavors to address the growing interest in questions about how the activities of complex systems can be coordinated. The theory is founded on the idea of conceptual separation of two types of activities that are present within any process: activities that directly contribute to the output of the process and additional activities called coordination mechanisms, which must be carried out in order to manage various interdependencies among activities and resources. Figure 1 illustrates the three classifications of value chain processes. On it, management competences are depicted as sets of elements (e.g. activities, skills, capabilities) which are applied throughout core processes. 


\section{Management}

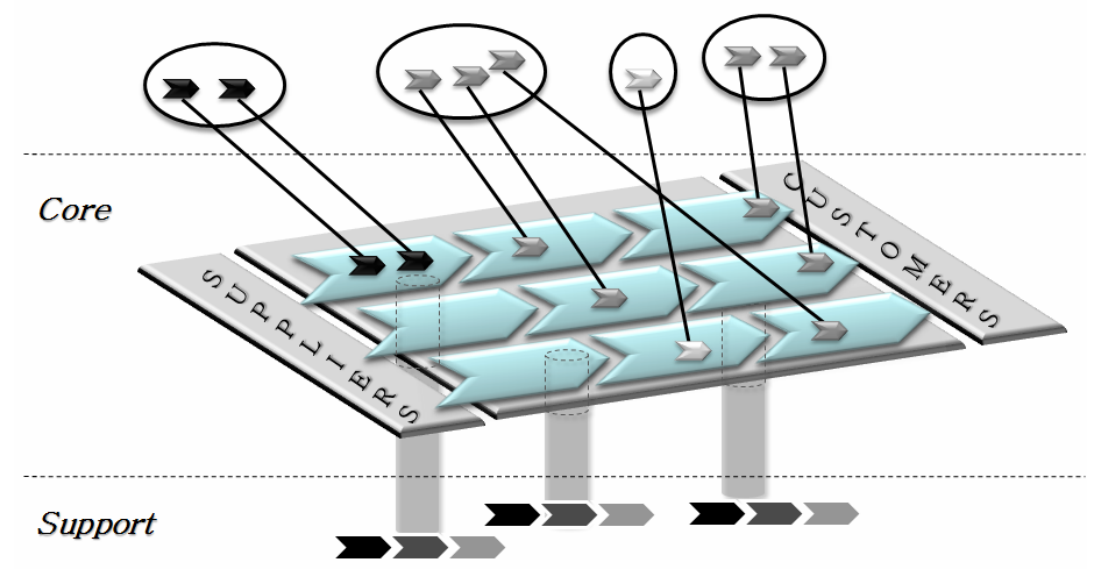

Fig. 1. Value Chain Processes Classification Framework

\section{Value Chain Core Processes Framework}

Following the above classification for value chain processes, Azevedo et al. [2] propose a core processes framework. Based on a content analysis of over 184 articles, the authors identify seven core processes for manufacturing companies located in the middle of a value chain. The processes are: strategic planning, sales and operations planning, value commitment, order fulfilment, inventory replenishment, product return and value development. Each process scope is introduced in the following:

- Strategic Planning Process - is the set of activities in charge of determining the direction and scope of an organization over the long term which achieves advantages for the organization through its configuration of resources within a changing environment, to meet the needs of markets and fulfil stakeholder expectations.

- Sales \& Operations Planning Process - is the process responsible for the deployment of the company's strategic drivers into a set of aligned cross-departmental plans. While strategic planning is in charge of the company's direction and scope over the long term, the $\mathrm{S} \& \mathrm{OP}$ responsibilities lay throughout the tactical horizon.

- Value Commitment Process - is the process in charge of conducting the mutual discussion and arrangement of the terms of a sales order. To do so, it spans from the initial dialogue between the company and the customer when dealing with a request up to the moment when the customer inquiry is converted into an order for the vendor. This moment is represented in the framework by the Commitment Point (C.P.).

- Order Fulfilment Process - covers all related activities from the moment the order is received to the instant the customer obtains the product and the seller collects the agreed compensation. In other words, it encompasses all (order-driven) activities upwards to the Decoupling Point (D.P.). 
- Inventory Replenishment Process - as the counterpart of the order fulfilment process, the responsibilities of the inventory replenishment process span from the update of the forecast as well as inventory consumption along the value chain network up to the moment when the material is replaced in its exact inventory position.

- Product Return Process - this core process begins when a customer decides to return one or more products to the seller and it ends with the disposal of the product by the seller and the provision of a solution for the customer.

- Value Development Process - invokes the whole series of steps from the generation of an idea or an opportunity to the launching of a product/service (or a combination of both) that adds value to end users, the company and the value chain.

\section{Competence-Based Value Chain Management Processes}

In this section we demonstrate how value chain processes are correlated to the competence theory. The following introduces the concept of organizational competence, which will allow us to propose and illustrate management processes as competences to be built and leveraged within organizations.

\subsection{Competence-Based Approach}

Conceptualizing and analyzing the competences of organizations has become a key focus of management thinking in recent decades. The term "competence" is defined as the ability to sustain the coordinated deployment of assets in ways that help a firm achieve its goals [14]. Therefore, its study relies on the investigation of the association between a company's internal characteristics and market value creation [7].

In order to avoid terminological confusion, Sanchez et al. [12] define the following key elements involved in the conceptualization of organizational competence:

- Assets: anything tangible or intangible the firm can use in its processes for creating, producing and offering its products (goods or services) to a market;

- Capabilities: repeatable patterns of action (activities) in the use of assets to create, produce and/or offer products to a market. Because capabilities are intangible assets that determine the use of tangible assets and other kinds of intangible assets, capabilities are considered to be an important category of assets.

- Skills: Special forms of capability usually embedded in individuals or teams that are useful in specialized situations or related to the use of a specialized asset.

- Knowledge: the set of beliefs held by an individual about casual relationships among phenomena. To the extent that a group of individuals within a firm has a shared set of beliefs about causality, that set of shared beliefs constitutes organizational knowledge. Since competence implies an intention to achieve some desired result (goal) through action, and since action-taking requires notions of cause and effect, knowledge and the application of knowledge through action are at the foundation of the concepts of skills, capabilities and (ultimately) competence.

Other elements related to the concept of competence are the organizational systems or also denominated management routines [9] or even controls and incentives [14]. 
Organizational systems are the conjunct of systems such as rules, norms, values, rewards, supervision etc. which govern the way a firm obtains and allocates resources to competence building and competence leveraging activities. Their role is one of monitoring and motivating the value-creating processes envisioned by a given strategy [14].

In addition, in order to support the identification and development of competences within organizations, Sanchez [14] discusses four core natures of any organizational competence: dynamic, systemic, cognitive and holistic.

- Dynamic nature: a central objective in competence theory and practice is the understanding of the co-evolutionary dynamics of environmental and organizational change and their roles in shaping organizational competences [13]. Therefore, a competence must include the ability to respond to the dynamic nature of an organization's external environment and of its own internal processes;

- Systemic nature: company competences must include an ability to manage the systemic nature of organizations and of their interactions with other organizations. The requirement of coordination of assets (tangible and intangible) addresses this dimension of competence, either just within the organization's boundaries (called firm-specific assets) or also beyond the boundaries of the firm (called firm-addressable assets);

- Cognitive nature: competence must include an ability to manage the cognitive processes of an organization. The requirement of deployment of assets - directing organizational assets to specific value-creating activities - addresses this dimension of competence;

- Holistic nature: it involves the requirement of goal achievement for the multiplicity of individual and institutional interests that intermingle in and are served through any organization. Thus, the definition of organizational competence recognizes the existence of multiple stakeholders and the importance of meeting expectations of all providers of essential resources in sustaining the value-creating processes of an organization.

\subsection{Value Chain Management Processes as Management Competences}

Here we present how value chain management processes should be supported by competence theory. In reality, we claim that management processes should be understood as management competences when processes-oriented business models are pursued. We justify this proposition based on two central arguments: first the misinterpretation caused by the wording "process" in the term "management process" and second, the alignment of the competence-based approach to what is expected from management processes. We state both arguments in further detail.

As previously mentioned, there is still a lot of ambiguity in the definition of management processes in the literature. Davenport [5] asserts that the reason for this ambiguity lies in the fact that the term "management process" results in a kind of oxymoron when the word "process" gives the sense of a collection of sequenced activities with clear inputs and outputs; in management functions this rationality is not clearly evident. In connection with this issue, Mentzer et al. [11] prefer defining management processes as broad knowledge domains. 
In addition, envisaging management functions simply as sets of activities (e.g. demand management process) veils the importance of additional management aspects such as organizational systems (e.g. decision rules, values, and incentive structure), skills as well as individual and organizational knowledge. These aspects are of crucial importance when coordinating core and support processes towards the organization's strategic goals. By taking this perspective, the definition of management process becomes aligned with the four natures of a competence introduced by Sanchez [14]. By being in charge of translating and coordinating the company's changing environment by decisions throughout its core processes, management activities must present dynamic behaviour in order to cope with the complexity of the environment in which the company is situated. Management processes must also be systemic in order to be able to address internal elements of an organization or along the value chain. The cognitive aspects of management processes are in charge of defining and implementing the appropriate set of coordination activities throughout core and support processes in order to assure the objective of the management domain. Finally, management processes must also present holistic behaviours once they deal with different expectations of multiple stakeholders across the value chain.

Based on the above statements we suggest denominating "management processes" as "management competences" in the value chain processes literature in order to eliminate the ambiguity inherent in the former nomenclature as well as to allow further exploratory research that will hopefully capture more elements of the business environment within processes-based value chain frameworks.

\subsection{An Illustrative Example of Value Chain Management Competence}

Based on the debate presented, we illustrate how management processes might be addressed as competences within organizations. In order to do so, we selected the demand management competence as the object of our investigation. The selection of the demand management domain relies on its significant position in the agendas of academics and practitioners.

However, it is important to emphasize that the descriptions provided below do not intend to be assumed as a reference model for demand management competence. On the contrary, they simply aim to illustrate the competence deployment. This lack of confidence is related to the fact that competence building and competence leverage is conditional on market characteristics [9], which means that reference models for management competences should be proposed according to firms' environments contingent characteristics. As for this concern, Sanchez [14] asserts that "competence often appears to be contingent - i.e., to be capable of creating value in certain kinds of competitive contexts, but not necessarily in others."

Demand management is defined in the $11^{\text {th }}$ edition of the APICS dictionary as the function of recognizing all demands for goods and services to support the marketplace. It involves prioritizing demand when supply is lacking. Proper demand management facilitates the planning and use of resources for profitable business results. Therefore, Table 1 presents some examples of demand management activities which may exist in different core processes of an organization. Although omitted here, activities flows are usually presented together with other related elements such as actors, resources (assets) and information [3]. 
Table 1. Illustrative example of activities of the demand management competence

\begin{tabular}{|c|l|}
\hline Processes & \multicolumn{1}{c|}{ Activities } \\
\hline $\begin{array}{c}\text { Strategic } \\
\text { Planning }\end{array}$ & $\begin{array}{l}\text { Forecast long-term sales volume } \\
\text { Forecast market conditions }\end{array}$ \\
\hline $\begin{array}{c}\text { Sales \& } \\
\text { Operations Planning }\end{array}$ & $\begin{array}{l}\text { Forecast medium-term sales volumes } \\
\text { Adjust demand according to supply restrictions }\end{array}$ \\
\hline $\begin{array}{c}\text { Value } \\
\text { Commitment }\end{array}$ & $\begin{array}{l}\text { Offer appropriate value to customers (e.g. delivery } \\
\text { lead-time and prices) } \\
\text { Prioritize commitments when supply is lacking }\end{array}$ \\
\hline $\begin{array}{c}\text { Inventory } \\
\text { Replenishment }\end{array}$ & Adjust short-term forecasts \\
\hline
\end{tabular}

Once the activities have been identified, it makes the deployment of complementary competence perspectives essential to guarantee proper pursuit of the firm's goals. Table 2 illustrates fundamental organizational systems, skills and knowledge for two demand management activities.

Table 2. Example of a competence perspective for demand management activities

\begin{tabular}{|c|l|l|l|}
\hline Activities & \multicolumn{1}{c|}{ Org. Systems } & \multicolumn{1}{c|}{ Skills } & \multicolumn{1}{c|}{ Knowledge } \\
\hline $\begin{array}{c}\text { Forecast } \\
\text { medium-term sales } \\
\text { volumes }\end{array}$ & $\begin{array}{l}\text { Value: information } \\
\text { transparency } \\
\text { Rewards based on } \\
\text { forecast accuracy }\end{array}$ & $\begin{array}{l}\text { Planning skills } \\
\text { Analytical } \\
\text { skills }\end{array}$ & $\begin{array}{l}\text { Statistics } \\
\text { Customer and } \\
\text { market behaviour }\end{array}$ \\
\hline $\begin{array}{c}\text { Prioritize } \\
\text { commitments } \text { when } \\
\text { supply is lacking }\end{array}$ & $\begin{array}{l}\text { Rule: optimize } \\
\text { profitability and } \\
\text { service level }\end{array}$ & $\begin{array}{l}\text { Optimization } \\
\text { Strategic } \\
\text { vision }\end{array}$ & $\begin{array}{l}\text { Operations } \\
\text { research } \\
\text { Company strategy }\end{array}$ \\
\hline
\end{tabular}

\section{Conclusions}

This article has sought to open innovative debates concerning processes-oriented value chains. To accomplish this, it recovers the fundamental principles of competence theory in order to propose a more robust approach when dealing with management processes.

According to the findings presented, firms' business models are composed of core (and support) processes as well as management competences. While core processes are needed to realize business goals by enabling goods and services to reach external customers, management competences are in charge of setting the proper set of coordination activities, organizational systems, skills and knowledge through core and support processes in order to properly control and coordinate their use of assets towards firm's goals. This approach differs from the traditional proposition by assuming the unstructured and discontinuous behaviours of management activities as well as by integrating additional organizational aspects such as norms, rules, skills and knowledge into the management processes perspective. 
In this way, we aim to eliminate the oxymoron caused by the term management process as well as to allow further explorative research which will hopefully capture more elements of the business environments within processes-based value chain frameworks. For instance, in the academic arena, we have been applying the proposed perspective of value chain processes in order to investigate the integration between the value chain and revenue management bodies of knowledge for commodity-type manufacturing environments.

\section{References}

1. Aguilar-Saven, R.S.: Business Process Modelling: Review and Framework. Int Journal Prod Econ. 90, 129-149 (2004)

2. Azevedo, R.C., D’Amours, S., Rönnqvist, M.: Core Supply Chain Management Business Processes - A literature-based framework proposition. In: The Third World Conference on Production and Operations Management, Tokyo, Japan (2008)

3. Boucher, X., Kühn, H., Janke, J.: Integrated Modelling and Simulation of InterOrganizational Business Processes. In: 4e Conférence Francophone de Modélisation et SIMulation, Tousouse, France (2003)

4. Davenport, T.H., Short, J.E.: The new industrial engineering: information technology and business process redesign. Sloan Management Review 31-4, 11-27 (1990)

5. Davenport, T.H.: Process innovation, reengineering work through information technology. Harvard Business Review, Boston (1993)

6. Hammer, M.: Reengineering work: don't automate, obliterate. Harvard Business Review 68-4, 104-112 (1990)

7. Harmsen, H., Jensen, B.: Identifying the determinants of value creation in the market - A competence-based approach. Journal of Business Research 57, 533-547 (2004)

8. Lambert, D.M., Garcia-Dastugue, S.J., Croxton, K.L.: An evaluation of process-oriented supply chain management frameworks. Journal of Business Logistics 26-1, 25-49 (2005)

9. Lewis, M.A., Gregory, M.J.: Developing and Applying a Process Approach to Competence Analysis. In: Sanchez, R., Heene, A., Thomas, H. (eds.) Dynamics Competence-Based Competition - Theory and Practice in the New Strategic Management. Pergamon, Oxford (1996)

10. Malone, T.W., Crowston, K.: The Interdisciplinary Study of Coordination. ACM Computing Surveys 26-1, 87-119 (1994)

11. Mentzer, J.T., Myers, M.B., Stank, T.P.: Handbook of Global Supply Chain Management. Sage Publications, Thousand Oaks (2007)

12. Sanchez, R., Heene, A., Thomas, H.: Introduction: Towards the Theory and Practice of Competence-Based Competition. In: Sanchez, R., Heene, A., Thomas, H. (eds.) Dynamics Competence-Based Competition - Theory and Practice in the New Strategic Management. Pergamon, Oxford (1996)

13. Sanchez, R., Heene, A.: Reinventing Strategic Management: New Theory and Practice for Competence-based Competition. Eur. Manag. Journal 15-3, 303-317 (1997)

14. Sanchez, R.: Understanding competence-based management - Identifying and managing five modes of competence. Journal of Business Research 57, 518-532 (2004)

15. Stadtler, T.J., Kilger, C.: Supply Chain Management and Advanced Planning - concepts, models, software and case studies, 3rd edn. Springer, Heidelberg (2004) 